\title{
Resolving vertical and east-west horizontal motion from differential interferometric synthetic aperture radar: The L'Aquila earthquake
}

\author{
G. Dalla Via, ${ }^{1}$ M. Crosetto, ${ }^{2}$ and B. Crippa ${ }^{3}$ \\ Received 19 July 2011; revised 19 December 2011; accepted 21 December 2011; published 18 February 2012. \\ [1] Analysis of surface coseismic displacement has already been obtained for the \\ 6 April 2009 L'Aquila (central Italy) earthquake from differential interferometric synthetic \\ aperture radar (DInSAR) data. Working jointly on ascending and descending DInSAR \\ data makes for a step forward with respect to published preliminary estimates: we process \\ data in order to retrieve a continuous displacement pattern, both in the vertical and \\ horizontal directions, the latter being limited to the eastward component because of the \\ low sensibility of the SAR images used to resolve northward motion. Our analysis provides \\ new insights on the horizontal component of displacement, obtaining a clear picture \\ of eastward displacement patterns over the epicentral area. This result is noteworthy, \\ as until now little information has been available on horizontal displacement following \\ normal-fault events in the central Apennines (Umbria-Marche, 1997, and L'Aquila, 2009), \\ given the lack of dense GPS networks, the only available source of horizontal displacement \\ data in this area. Inverted fault characteristics from such data also show noteworthy \\ differences compared to previous studies, localizing the Paganica fault as the causative \\ fault for the earthquake.
}

Citation: Dalla Via, G., M. Crosetto, and B. Crippa (2012), Resolving vertical and east-west horizontal motion from differential interferometric synthetic aperture radar: The L'Aquila earthquake, J. Geophys. Res., 117, B02310, doi:10.1029/2011JB008689.

\section{Introduction}

[2] Differential interferometric synthetic aperture radar (DInSAR) interferograms provide a quick look at the displacement of the portion of Earth's surface that has been struck by an earthquake along the line of sight (LOS) of the satellite. The pioneering work by Massonnet et al. [1993] showed that the set of fringes in the earthquake area provide a first estimate of coseismic displacements; a similar result was obtained for the $M_{W}=6.3 \mathrm{~L}$ 'Aquila earthquake, 6 April 2009, in central Italy and displacement data sets were used to infer fault characteristics by means of analytic models, as done by Anzidei et al. [2009] and Atzori et al. [2009], or numerical FE models also accounting for medium heterogeneity [Trasatti et al., 2011]. Working on ascending and descending DInSAR data makes for a step forward with respect to these preliminary estimates of coseismic displacements. This was done for the L'Aquila earthquake using ENVISAT SAR data in order to retrieve a continuous displacement pattern, both in the vertical and horizontal directions, the latter concerning the east-west

\footnotetext{
${ }^{1}$ Department of Physics, Politecnico di Milano, Milan, Italy.

${ }^{2}$ Institute of Geomatics, Castelldefels, Spain.

${ }^{3}$ Department of Earth Sciences "A. Desio," Università degli Studi di Milano, Milan, Italy.

Copyright 2012 by the American Geophysical Union. 0148-0227/12/2011JB008689
}

motion because of the limitation of these data in observing south-north horizontal motion. It is worth mentioning that some studies [e.g., Fialko et al., 2001; Wright et al., 2004] use DInSAR data to resolve 3-D displacements. This approach was not used in this study because of the relatively small displacements in the south-north direction. We have derived from our analysis new insights into the horizontal component, which not only provides major constraints on slip distribution, complementing vertical coseismic displacements, but also allows us to gain a clear picture of horizontal displacements for the L'Aquila normal fault earthquake, unachievable until now for earthquakes that struck the central Apennines area (Umbria-Marche, 1997, and L'Aquila, 2009) because of the very limited number of GPS sites, which are the only available sources of horizontal displacement detection in the area.

\section{Seismotectonic Setting of the Area and Previous Studies}

[3] The 2009 L'Aquila main shock occurred on the Paganica-San Demetrio Fault System (PSDFS in Figure 1), a structure 15-20 km long running parallel to the Apennine belt (NW trending) and dipping SW. The fault system is composed of several $1-5 \mathrm{~km}$ subfaults, arranged in a dextral en-echelon geometry [Galli et al., 2010; Guerrieri et al., 2010]. Along the PSDFS evidence of ground coseismic effects was found; fault traces at surface consisted of vertical and horizontal offsets up to $10-15 \mathrm{~cm}$, especially along the 


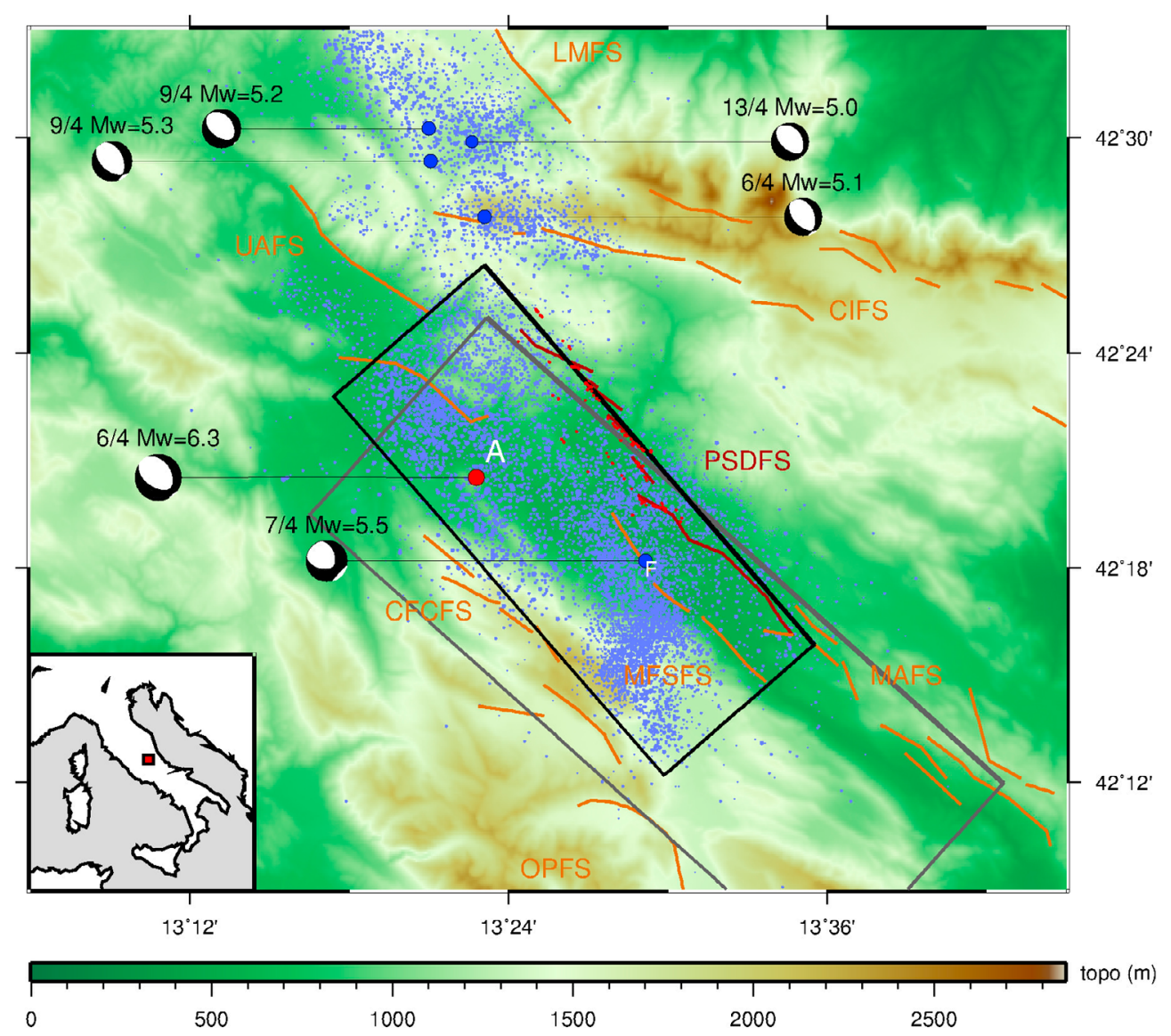

Figure 1. Epicentral area of the 2009 L'Aquila earthquake. The main shock is represented by the red circle, and aftershocks with $M_{W} \geq 5$ are represented as blue circles; for all events with $M_{W} \geq 5$ the focal mechanism is shown (source is global centroid moment tensor (GCMT), http://www.globalcmt.org). Minor aftershocks that occurred during the first month after the main shock are depicted as light blue points (all location data are from the Italian Seismic Instrumental and parametric Data-base (ISIDe), http://iside.rm.ingv.it/). Sites where Boncio et al. [2010] report evidence of coseismic ground deformation are plotted as red dots. Dark red lines correspond to the Paganica-San Demetrio Fault System (PSDFS), and orange lines represent the main fault systems of the area, modified from Galli et al. [2010] and Guerrieri et al. [2010] (LMFS, Laga Mountains Fault System; CIFS, Campo Imperatore Fault System; UAFS, Upper Aterno Fault System; CFCFS, Campo Felice-Colle Cerasitto Fault System; MAFS: Middle Aterno Fault System; MFSFS, Monticchio-Fossa-Stiffe Fault System; OPFS, Ovindoli- Piano Pezza Fault System). Modeled faults are also reported (run 0 fault, gray solid line; run 1 fault, solid black line). The positions of the city of L'Aquila (white A) and the village of Fossa (white F) are also reported. In the inset, the red rectangle represents the geographic frame of the epicentral area, as plotted in the following figures.

central and the NW portion of the fault system [EMERGEO Working Group, 2010; Falcucci et al., 2009; Boncio et al., 2010]. The SE segment, known as San Demetrio fault, trends approximately $\mathrm{N} 130^{\circ}$ and continues with minor gaps into the Middle Aterno valley Fault System (MAFS in Figure 1); the NW segments are known as the Paganica fault and trends $\mathrm{N} 140^{\circ}-\mathrm{N} 145^{\circ}$. The Upper Aterno Fault System (UAFS), placed on the hanging wall of the Laga Mountain Fault System (LMFS), falls along the NW extension of the Paganica fault. The alignment is delimited by the Campo Imperatore Fault System (CIFS) about $20 \mathrm{~km}$ to the NE and, to the SW, by the Colle Cerasitto-Campo Felice Fault System (CFCFS), the Ovindoli-Piano Pezza Fault System (OPFS), and the Fucino Fault System (FFS).
[4] The region is historically known to be prone to moderate to strong earthquakes, driven by the SW-NE extension of the Apennines belt at a rate of about 3-5 mm $\mathrm{yr}^{-1}$ according to D'Agostino et al. [2008]. Such a deformation is accommodated by normal faulting on lineaments parallel to the Apennines (SE trending), dipping mostly toward SW, although minor antithetic faults exist. Most fault systems consists of several subparallel segmented splays, and because of the superposition of such near-parallel faults, it is difficult to precisely identify the fault plane that was the source for historical earthquakes. However, almost all authors recognize the Paganica-San Demetrio Fault System as the source of the 1461 quake (intensity X MCS, $M_{W}=6.4$ ). The 1703 quake (intensity X MCS, $M_{W}=6.7$ ) 
originated on the UAFS, possibly also involving PSDFS, while the 1349 (intensity IX MCS) event originated on the CFCFS, placed on the hanging wall of the PSDFS and parallel to it. Other events $(1762,1850)$ struck the MAFS, on the SE extension of the PSDFS. The most important recent event in the area was the 1915 Avezzano earthquake $\left(M_{W}=7.0\right)$, originating in the Fucino valley fault system, located a short distance outside the southern bounds of Figure 1, on the SE extension of the CFCFS and OPFS alignment.

[5] All of these events originated from SW dipping, normal faults according to Guerrieri et al. [2010], Galli et al. [2010, 2011], Atzori et al. [2009], and references cited therein. Galli et al. [2011] infer from paleoseismological investigations on the PSDFS that the 1461 and 2009 events may be very similar in many respects, such as position, magnitude, and macroseismic effects. Moreover, they suggest the existence of a seismic barrier separating the PSDFS and the UAFS, playing an important role on magnitudes of earthquakes striking the PSDFS: 1461 and 2009 events stopped at the barrier, leading to $M_{W} \sim 6.3$ earthquakes. To the contrary, the 1703 event could have broken the barrier leading to a rupture involving both the PSDFS and the UAFS, thus generating an earthquake of up to $M_{W}=6.7$.

[6] The 2009 sequence started as a seismic swarm in December 2008 (with foreshocks $M_{L} \geq 4.1$ ) and culminated on 6 April 2009 with the $M_{W}=6.3$ main shock striking the PSDFS at about $9 \mathrm{~km}$ of depth, close to its lower edge and propagating upward and to the SE along the fault according to Cirella et al. [2009]. After the main shock, an important swarm of aftershocks (blue dots in Figure 1) followed [Chiarabba et al., 2009]; five aftershocks with $M_{W} \geq 5$ (according to global centroid moment tensor solutions, GCMT, http://www.globalcmt.org; see Table 1 for details) were recorded, the greatest of which ( 7 April, $M_{W}=5.5$ in GCMT and reported as $M_{W}=5.6$ by Atzori et al. [2009]) struck near the Fossa village. The causative fault of this event is still debated since its hypocenter was located at approximately $15 \mathrm{~km}$ of depth, approximately $5 \mathrm{~km}$ below the main swarm of aftershocks that occurred on the main fault plane. Moreover, the lack of other aftershocks in the volume surrounding the hypocenter makes it impossible to identify the preferred solution between the two possible nodal planes [Chiarabba et al., 2009; Di Luccio et al., 2010]. Some authors have noted that the epicenter lays in the planimetric projection of the shallower antithetic Fossa fault (on the Monticchio-Fossa-Stiffe Fault System, MFSFS), and Pino and Di Luccio [2009] infer that the source for the "Fossa" event was probably antithetic to the PSDFS. Nonetheless, it is improbable that the MFSFS was the source of this event, as the hypocenter is buried $5 \mathrm{~km}$ below it. The other four large aftershocks struck around Campotosto, $20 \mathrm{~km} \mathrm{NW}$ of L'Aquila and were possibly associated with a reactivation at depth of the southernmost portion of the LMFS.

[7] The main event has been thoroughly investigated by different disciplines: field and structural geology, geomorphology, seismology, paleoseismology and geodesy (DInSAR, GPS, leveling lines). Evidence of ground deformation was found on the surface, mainly in correspondence of the Paganica and San Demetrio faults, by the EMERGEO Working Group [2010], Boncio et al. [2010], Blumetti et al.
[2009], and Falcucci et al. [2009], among others. Both the coseismic and the early postseismic phases had been investigated with geophysical [Wilkinson et al., 2010] and geodetic methods, and investigations of fault characteristics were carried out by means of GPS data inversion [Anzidei et al., 2009; Cheloni et al., 2010], strong motion and GPS data inversion [Cirella et al., 2009] and inversion of DInSAR data, alone or jointly with other geodetic data [Atzori et al., 2009; Walters et al., 2009; Guerrieri et al., 2010; Trasatti et al., 2011; De Natale et al., 2011].

[8] Geodetic data inversions (see Table 2 for comparison of fault parameters; a planimetric view of modeled faults is proposed in Figure S1 in the auxiliary material) differ on a relevant point: whether or not the on-fault rupture reached the surface. ${ }^{1}$ Atzori et al. [2009] (in both uniform and distributed slip models) and Cirella et al. [2009] place the top of the fault at depth, with the former explicitly proposing that faulting did not reach the surface. Additionally, Walters et al. [2009], Anzidei et al. [2009], Cheloni et al. [2010], and Trasatti et al. [2011] use both a uniform and a variable slip model for the fault, the former utilized to constrain fault parameters and the latter to infer slip distribution. When uniform slip is considered in these models, they obtain a fault model buried at depth with the top edge of the fault in the $0.5-3 \mathrm{~km}$ range. As these investigators let their variable slip fault models reach the surface, in most cases a small amount of slip results on superficial patches, corresponding to surface evidence of ground rupture. De Natale et al. [2011] adopt a variable slip model to invert DInSAR data, obtaining a pattern of maximum deformation centered at $4 \mathrm{~km}$ of depth, but also some shallow patches slipping just below the ruptured part of the Paganica fault. Last, Guerrieri et al. [2010] let the top of their fault model reach the surface and note in their discussion that ground coseismic effects correlate well with slip on patches at the top of their fault. Guerrieri et al. [2010] is also the only one to model the main shock with two adjacent faults with different strikes to mimic the change in strike between the San Demetrio and Paganica faults, as noted by Boncio et al. [2010] in their geological reconstruction of the fault.

[9] Another important difference can be found in the strike angles used by different models, ranging between $133^{\circ}$ and $144^{\circ}$; it is noteworthy that these angles follow the trending angles of the San Demetrio fault and Paganica fault, respectively, the two main structures involved in the main shock. This may suggest that depending on which data set (DInSAR, GPS, or strong motion) has been used for constraining fault parameters, one of the two faults somehow becomes dominant in inversion. Fault dimensions also differ significantly, especially when uniform or distributed slip models are considered, the latter generally being larger.

[10] The inferred seismic moment varies by up to $25 \%$ among different fault models (with the exception of that of Trasatti et al. [2011], which is lower than others), but there is a general concordance among distributed slip models in obtaining an along-strike elongated (also bilobed for some authors) pattern for fault areas undergoing significant slip, with the pattern starting just above the hypocenter and continuing to the SE (to the right of the fault). In most

\footnotetext{
${ }^{1}$ Auxiliary materials are available in the HTML. doi:10.1029/ 2011 JB008689.
} 
Table 1. Parameters of Main Shock (Event 1) and Aftershocks (Events 2-6) with $M_{W} \geq 5$, According to GCMT

\begin{tabular}{lcccccccccc}
\hline Event & Date $^{\mathrm{a}}$ & $\begin{array}{c}\text { Time } \\
(\mathrm{UTC})\end{array}$ & $\begin{array}{c}\text { Latitude }^{\mathrm{b}} \\
(\mathrm{deg})\end{array}$ & $\begin{array}{c}\text { Longitude }^{\mathrm{b}} \\
(\mathrm{deg})\end{array}$ & $\begin{array}{c}\text { Depth }^{\mathrm{b}} \\
(\mathrm{km})\end{array}$ & $\begin{array}{c}\text { Strike }^{\mathrm{c}} \\
(\mathrm{deg})\end{array}$ & $\begin{array}{c}\text { Dip }^{\mathrm{c}} \\
(\mathrm{deg})\end{array}$ & $\begin{array}{c}\text { Rake }^{\mathrm{c}} \\
(\mathrm{deg})\end{array}$ & $\begin{array}{c}M_{w}{ }^{\mathrm{c}} \\
\left(10^{18}{ }^{18}\right. \\
\mathrm{Nm})\end{array}$ \\
\hline 1 & 6 Apr 2009 & $01: 32$ & 42.342 & 13.380 & 8.3 & 120 & 54 & -113 & 6.3 & 3.66 \\
3 & 6 Apr 2009 & $23: 15$ & 42.463 & 13.385 & 9.7 & 135 & 53 & -108 & 5.1 & 0.05 \\
$3^{\mathrm{d}}$ & 7 Apr 2009 & $17: 47$ & 42.303 & 13.486 & 17.1 & 101 & 57 & -138 & 5.5 & 0.25 \\
4 & & & & & & 345 & 55 & -41 & & \\
5 & 9 Apr 2009 & $00: 53$ & 42.489 & 13.351 & 11.0 & 129 & 50 & -111 & 5.3 & 0.16 \\
6 & 9 Apr 2009 & $19: 38$ & 42.504 & 13.350 & 9.3 & 122 & 54 & -109 & 5.2 & 0.08 \\
\hline
\end{tabular}

${ }^{a}$ For event 3 ("Fossa" event) both nodal planes are listed.

${ }^{\mathrm{b}}$ From global centroid moment tensor (GCMT; http://www.globalcmt.org/).

${ }^{c}$ From the Italian Seismic Instrumental and parametric Data-base (ISIDe; http://iside.rm.ingv.it/).

${ }^{\mathrm{d}}$ Conjugate plane.

models, the maximum slip (approximately $0.7-1.0 \mathrm{~m}$ ) occurs at 4-6 km of depth between Fossa and L'Aquila. This means that the earthquake started with a low-amplitude slip and propagated toward the surface (and to the SE) with increased slip values [Cirella et al., 2009; De Natale et al., 2011].

\section{DInSAR Method}

[11] The DInSAR method makes it possible to recover the vertical and eastward components of the terrain displacement by exploiting the ascending and descending SAR data acquired on a given area. A straightforward expression (see Appendix A) applied to the interferometric phases acquired with the two different orbit modalities gives the components of movement. This was applied to study the L'Aquila (Italy) earthquake event that occurred on 6 April 2009, using the ENVISAT SAR images made available by the European Space Agency (ESA). We used six SAR-SLC images acquired by the ENVISAT-ASAR satellite, three in ascending and three in descending mode. For each acquisition mode, two images were acquired before and one after the main event. From this data set four interferograms were computed (Figure 2; the main parameters are listed in Table 3). The time intervals and height ambiguities of the interferograms considered for the L'Aquila earthquake are suitable for interferometric processing and consequently for the estimation of coseismic surface deformation.

[12] The SAR images were processed with the DIAPASON software, using a multilook $1 \times 5$ (range and azimuth), which yields a pixel size of approximately $20 \times 20 \mathrm{~m}$. A 3 arcsec SRTM DEM was used to remove the topographic phase. The four interferograms are shown in sure 2. The high degree of similarity between the fringe patterns of these interferograms is noteworthy. The fringes visible in the epicentral area are characteristic of a surface-breaking (or nearly breaking) fault. However, not all fringes were caused by the earthquake: in addition to the displacement signature due to the main event and aftershocks, there are also other phase components due to atmospheric effects, residual orbital effects, and phase noise. The four interferograms present a good level coherence and unequivocally show the presence of an area with coseismic deformation, occurring within the time interval of each interferogram. In this case the time intervals of all interferograms include the earthquake of 6 April 2009 with a magnitude $M_{W}=6.3$, as well as the 7 April (Fossa), $M_{W}=5.5$, and the 9 April, $M_{W}=5.4$, events [Atzori et al., 2009].

[13] The generated interferograms are unwrapped to recover the principal value of the phases starting from the original phase values. The phase unwrapping is an ill-posed problem and the most critical point of the interferometric analysis, as noted by Chen and Zebker [2000]. This step is

Table 2. Parameters for Modeled Fault (Main Shock) in Previous Works, Modified and Integrated After the Supplementary Material of Cheloni et al. $[2010]^{\mathrm{a}}$

\begin{tabular}{|c|c|c|c|c|c|c|c|c|c|c|c|c|}
\hline Model & Kind & $\mathrm{Src}$ & $\begin{array}{l}\text { Lat. } \\
\text { (deg) }\end{array}$ & $\begin{array}{l}\text { Long. } \\
\text { (deg) }\end{array}$ & $\begin{array}{l}\text { Dep. } \\
(\mathrm{km})\end{array}$ & $\begin{array}{c}\mathrm{L} \\
(\mathrm{km})\end{array}$ & $\begin{array}{c}\mathrm{W} \\
(\mathrm{km})\end{array}$ & $\begin{array}{l}\text { Strike } \\
(\mathrm{deg})\end{array}$ & $\begin{array}{l}\text { Dip } \\
\text { (deg) }\end{array}$ & $\begin{array}{l}\text { Rake } \\
\text { (deg) }\end{array}$ & $\begin{array}{l}\text { Slip } \\
(\mathrm{m})\end{array}$ & $\begin{array}{c}\mathrm{M}_{0} \\
\left(10^{18} \mathrm{Nm}\right)\end{array}$ \\
\hline Anz09 & $\mathrm{U}$ & G & 42.39 & 13.41 & 0.0 & 13.0 & 15.7 & 140 & 55.3 & -98.0 & 0.49 & 3.02 \\
\hline Atz09 & $\mathrm{U}$ & $\mathrm{S}+\mathrm{G}$ & 42.39 & 13.40 & 1.9 & 12.2 & 14.1 & 133 & 47 & -103 & 0.56 & 2.90 \\
\hline Atz09 & $\mathrm{D}$ & $\mathrm{S}+\mathrm{G}$ & 42.42 & 13.38 & 0.7 & 20.0 & 14.0 & $133^{*}$ & $47 *$ & $-103^{*}$ & - & 2.70 \\
\hline Cir09 & $\mathrm{D}$ & $\mathrm{G}+\mathrm{SM}$ & 42.43 & 13.37 & 0.5 & 28.0 & 17.5 & 133 & 54 & Var. & - & 3.50 \\
\hline Wal09 & $\mathrm{U}$ & $\mathrm{S}$ & 42.41 & 13.40 & 3.0 & 12.2 & 10.7 & 144 & 54 & -105 & 0.66 & 2.80 \\
\hline Wal09 & D & $\mathrm{S}$ & 42.46 & 13.38 & 0.0 & 19.0 & 16.1 & $144 *$ & $54 *$ & $-105^{*}$ & - & 2.91 \\
\hline Che10 & $\mathrm{U}$ & $\mathrm{G}$ & 42.40 & 13.42 & 0.6 & 20.0 & 15.7 & 135.8 & 50.4 & -98.5 & 0.62 & 3.90 \\
\hline Che10 & D & G & 42.45 & 13.36 & 0.0 & 28.0 & 20.0 & $135.8^{*}$ & $50.4 *$ & $-98.5^{*}$ & - & 3.46 \\
\hline Gue10 & $\mathrm{D}$ & $\mathrm{S}$ & 42.42 & 13.41 & 0.0 & 18.5 & 16.5 & 133,147 & 45 & -90 & _- & 2.88 \\
\hline Den11 & D & $\mathrm{S}$ & 42.44 & 13.41 & 0.1 & 35.0 & 20.0 & 145 & 50 & -90 & - & 2.83 \\
\hline Tra11 & $\mathrm{U}$ & $\mathrm{S}+\mathrm{G}$ & 42.39 & 13.41 & 2.3 & 12.5 & 18.8 & 142 & 42 & -96 & 0.53 & 2.14 \\
\hline Tra11 & $\mathrm{D}$ & $\mathrm{S}+\mathrm{G}$ & 42.43 & 13.40 & 0.0 & 20.0 & 15.0 & 142 & 42 & Var. & - & $1.2-2.5$ \\
\hline
\end{tabular}

${ }^{\mathrm{a}}$ The considered models are Anz09, Anzidei et al. [2009]; Cir09, Cirella et al. [2009]; Wa109, Walters et al. [2009]; Che10, Cheloni et al. [2010]; Gue10, Guerrieri et al. [2010]; Den11, De Natale et al. [2011]; Tra11, Trasatti et al. [2011]. Kind indicates if the fault model uses a uniform slip (U) or a distributed slip (D). Src reports which data set has been inverted: GPS (G), DInSAR (D), or strong motion data (SM). The latitude (Lat.), longitude (Lon.), and depth (Dep.) of the top left corner of the modeled fault, its length (L), width (W), strike, dip, and rake (Var. stands for variable rake), the slip inferred (only) for uniform slip fault models, and the seismic moment $\left(\mathrm{M}_{0}\right)$ are also listed. An asterisk indicates that the value was derived from the uniform slip fault model. 

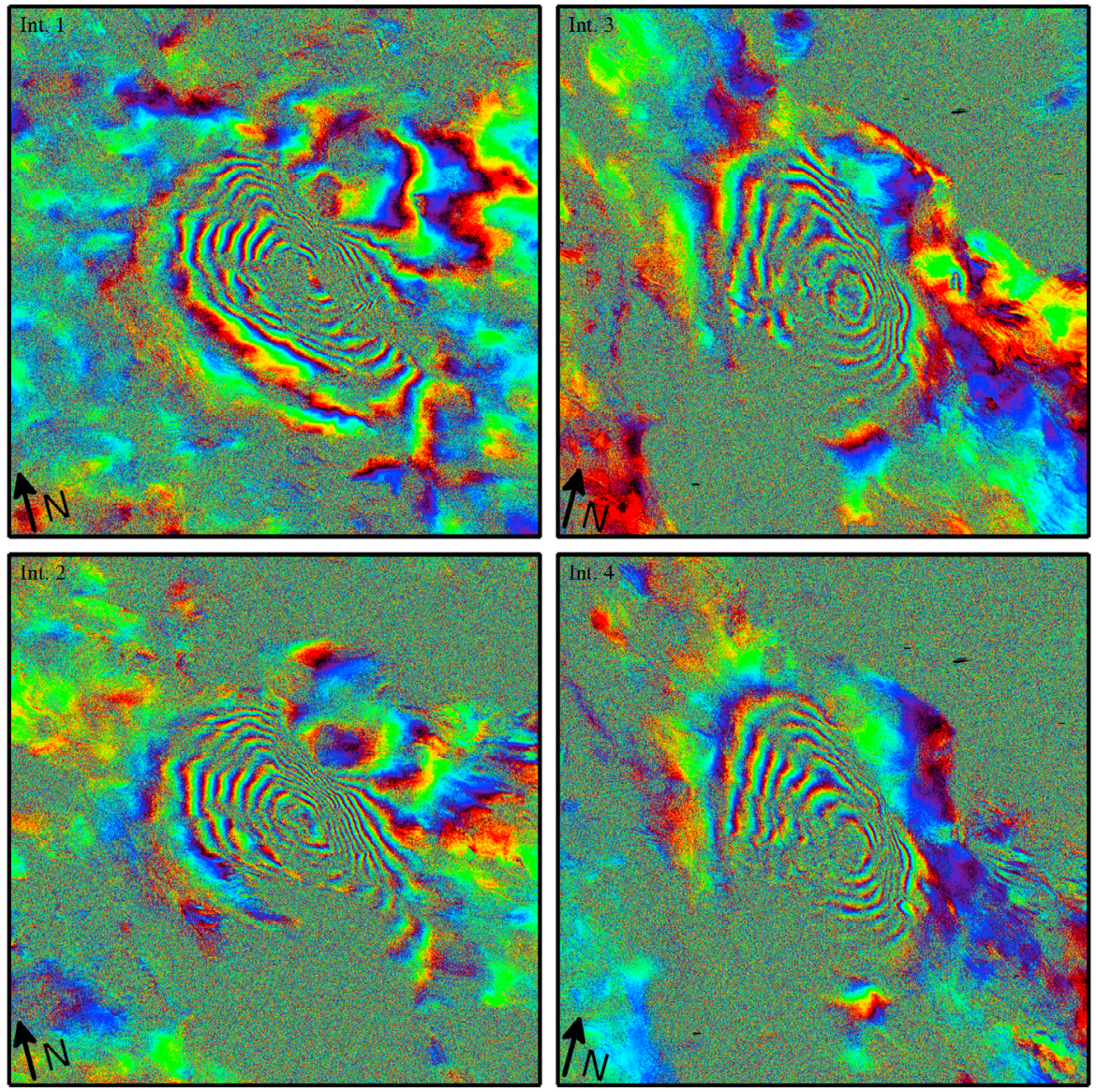

Figure 2. Interferograms generated by the six ENVISAT images, as in Table 1 (not geo-referenced).

influenced by several factors, and especially phase noise and high spatial gradients in the interferometric phases, which can be associated with strong spatial deformation gradients. The method proposed by Costantini [1998] was used to unwrap the phases. This method only exploits the pixels with high spatial coherence and estimates the unwrapped phases using a minimum cost flow algorithm.

[14] In order to check the phase unwrapping results, we exploited the availability of two pairs of interferograms that shared the same master image (Table 3): assuming that the displacement is due to the main earthquake event, the interferogram pairs have to show, on high coherence pixels, similar interferometric phase values. Checking the phases of interferograms with the same orbit mode by pixelwise comparison allows us to reject pixels with phase differences above $5 \mathrm{rad}$ (approximately $2.2 \mathrm{~cm}$ displacement along the LOS) and to average phase values for all remaining pixels. The 5 rad threshold was chosen because it was observed that aliasing adds a jump that is an integer multiple of $2 \pi \mathrm{rad}$ to the correct phase value, thus a difference greater than $2 \pi$ rad between unwrapped phases of correspondent pixels in two interferograms sharing the same master can be used as a quality test for detecting a probable aliasing.

[15] The next DInSAR processing step is the transformation from phase along-LOS displacement and phase geocoding in the WGS84 datum (Figure 3), to reference the displacements estimated from ascending and descending observations in a common reference system. The last step

Table 3. Parameters of the Four Interferograms Used in This Work ${ }^{\mathrm{a}}$

\begin{tabular}{|c|c|c|c|c|c|c|c|c|}
\hline \multirow[b]{2}{*}{ Int } & \multicolumn{2}{|c|}{ Slave Image } & \multicolumn{2}{|c|}{ Master Image } & \multirow[b]{2}{*}{ Track } & \multirow[b]{2}{*}{ Mode } & \multirow[b]{2}{*}{$\mathrm{Ha}(\mathrm{m})$} & \multirow[b]{2}{*}{$\theta(\operatorname{deg})$} \\
\hline & Date & Orbit & Date & Orbit & & & & \\
\hline 1 & 27 Apr 2008 & 32917 & 12 Apr 2009 & 37207 & 79 & D & -256 & 22.7512 \\
\hline 2 & $1 \mathrm{Feb} 2009$ & 36205 & 12 Apr 2009 & 37207 & 79 & D & 62 & 22.7574 \\
\hline 3 & 11 Mar 2009 & 36756 & 15 Apr 2009 & 37257 & 129 & A & -40 & 22.7568 \\
\hline 4 & 31 Dec 2008 & 35754 & 15 Apr 2009 & 37257 & 129 & A & -73 & 22.7604 \\
\hline
\end{tabular}

${ }^{\mathrm{a}}$ For each interferogram (Int), acquisition date and orbit are reported for the master and slave images, together with orbit track number and mode (A and D stand for ascending and descending, respectively), height ambiguity (Ha), and angle of incidence $(\theta)$. 


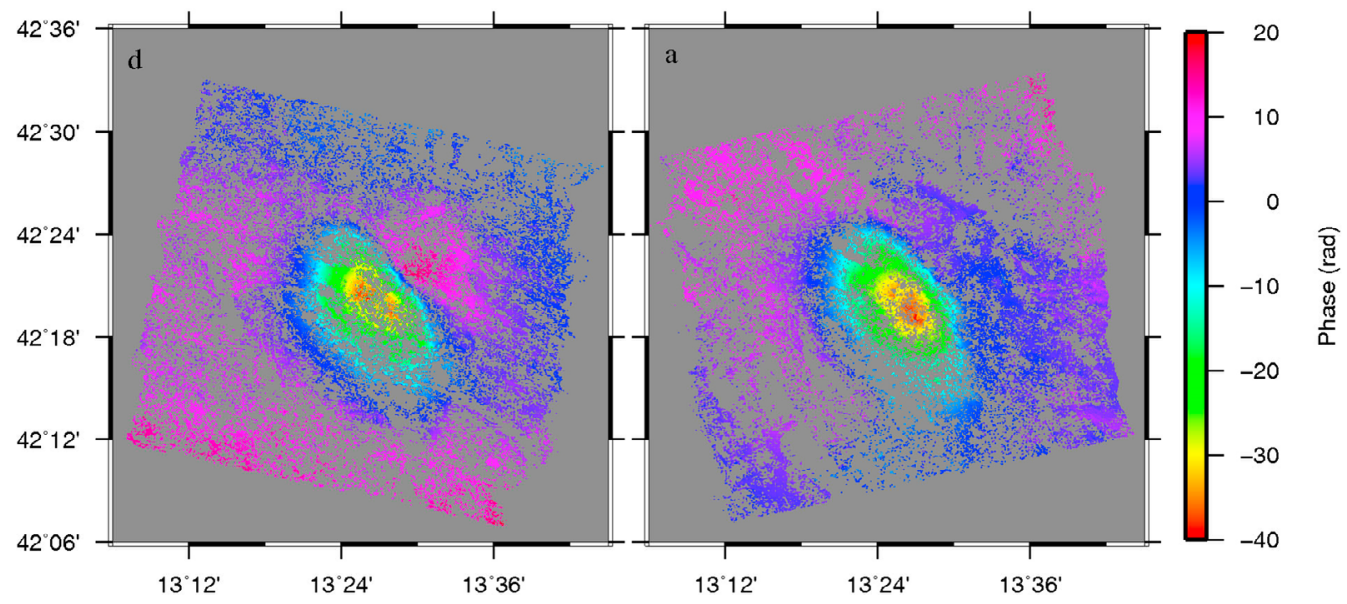

Figure 3. Unwrapped interferograms, ascending (a) and descending (d) modes, after checking the internal consistency of the unwrapping procedure.

is the estimation of the eastward and vertical coseismic displacement fields. This is obtained by taking geocoded pairs of neighboring ascending and descending points (points within $0.003^{\circ}$, approximately $300 \mathrm{~m}$ distance) and computing the two components of displacement using the expression reported in Appendix A.

[16] According to Wright et al. [2004], the availability of multilook interferograms helps constrain fault characteristics when trade-off between parameters exists (and this is the case, as discussed, e.g., by Atzori et al. [2009]). A full 3-D decomposition would be the best option for parameter estimation; in our case, because of the small diversity in viewing geometry and the relatively low amount of northward surface displacement, it was not possible to obtain for this earthquake values of northward displacement significantly greater than the measure errors. For this reason, we considered and computed only vertical and eastward components of displacement; moreover, $\mathrm{Z}$ and $\mathrm{E}-\mathrm{W}$ components of DInSAR-observed displacement can be compared directly with displacement data sets from the few GPS sites operating in the epicentral area [Anzidei et al., 2009].

[17] The resulting full resolution displacement fields are shown with model results in Figure 7 in section 5. Vertical motion (Figure 7a) is characterized by a large subsiding area (blue) overprinting the hanging wall of the fault, surrounded by a broad area of relative uplift (red). The eastward component of displacement (Figure 7d) is higher close to the top of the fault. On the hanging wall a blue stripe of westward displacement runs parallel to the fault strike. Westward displacement over the hanging wall alternates, almost symmetrically with respect to fault strike, with an area of eastward motion (in red) overprinting the footwall. Points near the fault strike seem to undergo a quite high deformation, and vertical deformation is predominant for points overprinting the center of the fault. Both vertical and eastward dislocation patterns depict a shallow, extensive normalfaulting event.

\section{Data Modeling}

[18] The availability of dense DInSAR data sets over the epicentral area allows us to describe the variation of fault parameters in a very refined way since, even when using a finely gridded fault, the number of observation points far exceeds the number of fault patches, resulting in a strongly overdetermined inverse problem. Minimizing the chi square functional with respect to the model parameters thus leads to the "best solution" of the problem. Although overdetermined, the problem may encounter numerical difficulties such as badly conditioned matrices or computational instabilities. Thus, even if unnecessary from a purely mathematical point of view, we prefer to introduce a penalized functional following the Lagrange's multipliers method, taking into account the model roughness (the penalization factor) over the fault [deGroot-Hedlin and Constable, 1990; Jonsson et al., 2002; Dalla Via et al., 2007]. This approach is suggested in the case of underdetermined or very unstable problems, but it is also a good choice for overdetermined problems in which the degree of smoothness/roughness over the model parameters has to be taken into account and evaluated. Thus, in this framework we are seeking a model which minimizes the misfit, given a limiting upper value for model roughness,

Table 4. Characteristics of Fault Models Used in This Paper ${ }^{\mathrm{a}}$

\begin{tabular}{ccccccccccc}
\hline Run & Strike (deg) & Dip (deg) & Rake $(\mathrm{deg})$ & L $(\mathrm{km})$ & W $(\mathrm{km})$ & E (deg) & N (deg) & Z (km) & PL (m) & BS (m) \\
\hline 1 & 133 & 47 & -103 & 36 & 20 & 13.3859 & 42.4160 & 0.1 & 2000 & 1000 \\
2 & 140 & 50 & Var. & 26 & 16 & 13.3845 & 42.4405 & 0.1 & 2000 & 1000 \\
3 & 140 & 50 & Var. & 26 & 16 & 13.3845 & 42.4405 & 0.1 & 500 & 20 \\
\hline
\end{tabular}

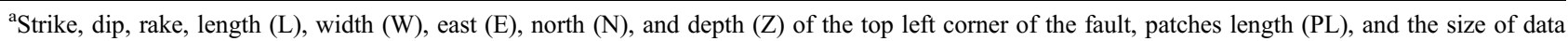
blocks (BS) are reported. 


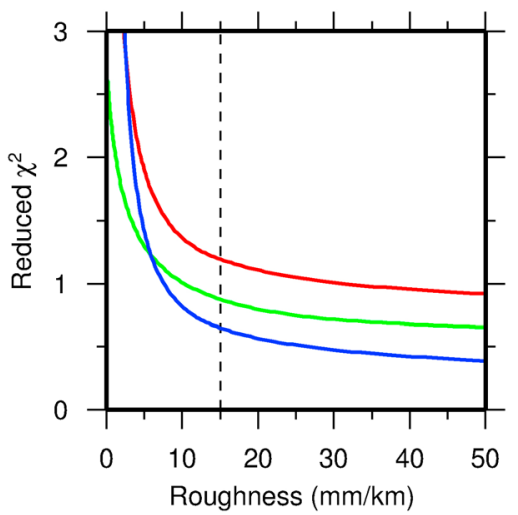

Figure 4. Parameter $\chi_{r}^{2}$ versus model roughness $\rho$, as obtained from the inversion of the fault model run 2 . The blue line shows the inversion of vertical data only. The green line shows the inversion of eastward data only. The red line shows the joint inversion of the two data sets. The vertical dashed line represents the roughness limit of $15 \mathrm{~mm} / \mathrm{km}$ chosen in the inversion.

or alternately, the smoothest model achieving a desirable, prefixed amount of allowed misfit. The penalized functional is cast as

$$
A(\mathbf{m})=\|\mathbf{W}(\mathbf{d}-\mathbf{G m})\|^{2}+\mu\|\partial \mathbf{m}\|^{2}
$$

or

$$
A(\mathbf{m})=(\mathbf{d}-\mathbf{G m})^{T} \mathbf{C}_{\mathbf{d}}^{-1}(\mathbf{d}-\mathbf{G m})+\mu(\partial \mathbf{m})^{T}(\partial \mathbf{m}),
$$

where $\mathbf{m}$ is the vector of modeled slip over the fault patches, $\mathbf{d}$ is the vector of observed deformation, $\mathbf{C}_{\mathbf{d}}$ is the data covariance matrix, a matrix cast in such a way that $\left(\mathbf{C}_{\mathbf{d}}\right)_{i i}=$ $\sigma_{i}^{2}$, with $\sigma_{i}$ being the error relative to the ith observation point, and $\mathbf{G}$ is the Green's function matrix representing the unit deformation over observation points given by each patch of the fault. Under the hypothesis of uncorrelated independent observations on SAR points, $\mathbf{C}_{\mathbf{d}}$ is diagonal. In the most complex case, the $\mathbf{G}$ matrix includes Green's functions computed for both eastward and vertical data, over the SAR points for both strike slip and dip slip components of each patch of the fault, plus coefficients for biases and tilts. The sought-after model vector $\mathbf{m}$ includes estimated slip magnitudes (both for the strike slip and dip slip components), offsets and tilts inferred for eastward and vertical data sets. With respect to a pure chi square minimization problem, represented by the first term on the right side of equation (1), a second penalization term was added, namely the model roughness $\rho(\mathbf{m})=\|\partial \mathbf{m}\|^{2}$, with $\partial$ being the matrix describing the finite difference operator between adjacent patches and $\mu$ the multiplier weighting the importance of misfit against model roughness.

[19] Inversion also includes an estimate of bias (or offset) for both vertical and eastward data possibly introduced by arbitrarily choosing the points where deformation is supposed to be null in differential data. We also introduced the estimation and correction for residual tilt, possibly still present after the unwrapping procedure. We also computed
Table 5. Summary of Inversion Results ${ }^{\mathrm{a}}$

\begin{tabular}{cccccc}
\hline Run & $\begin{array}{c}\text { Inverted } \\
\text { Data }\end{array}$ & $\chi_{r}^{2}$ & $\begin{array}{c}\text { Slip Minimum } \\
(\mathrm{m})\end{array}$ & $\begin{array}{c}\text { Slip Maximum } \\
(\mathrm{m})\end{array}$ & $\begin{array}{c}\mathrm{M}_{0} \\
\left(10^{18} \mathrm{Nm}\right)\end{array}$ \\
\hline 1 & $\mathrm{Z}$ & 1.09 & 0.000 & 0.697 & 2.24 \\
& $\mathrm{E}$ & 1.47 & 0.000 & 0.645 & 3.84 \\
& $\mathrm{Z}+\mathrm{E}$ & 1.52 & 0.000 & 0.597 & 2.26 \\
2 & $\mathrm{Z}$ & 0.63 & 0.030 & 0.580 & 3.40 \\
& $\mathrm{E}$ & 0.86 & 0.011 & 0.591 & 4.21 \\
& $\mathrm{Z}+\mathrm{E}$ & 1.15 & 0.018 & 0.626 & 3.07 \\
3 & $\mathrm{Z}$ & 0.28 & 0.000 & 0.740 & 3.23 \\
& $\mathrm{E}$ & 1.62 & 0.001 & 0.951 & 3.97 \\
& $\mathrm{Z}+\mathrm{E}$ & 1.71 & 0.000 & 0.987 & 3.39 \\
\hline
\end{tabular}

${ }^{\mathrm{a}}$ For each run, results for inversion of vertical data only $(\mathrm{Z})$, eastward data only (E), and both data sets are listed separately. The seismic moment is computed considering a rigidity of $30 \mathrm{GPa}$.

errors on modeled slip distribution, both in terms of standard deviation associated with the slip distribution and resolution study, as done by Trasatti et al. [2011]. Given equation (1), it is possible to recast it in a normal form equation (2), thus obtaining $\mathbf{m}$ as

$$
\mathbf{m}=\left(\mathbf{G}^{T} \mathbf{C}_{\mathbf{d}}{ }^{-1} \mathbf{G}+\mu \partial^{T} \partial\right)^{-1}\left(\mathbf{G}^{T} \mathbf{C}_{\mathbf{d}}\right) \mathbf{d}=\mathbf{G}^{-g} \mathbf{d},
$$

where $\mathbf{G}^{-g}$ is the so-called generalized inverse. It is easy to obtain model covariance matrix $\mathbf{C}_{\mathbf{m}}$ and model resolution matrix $\mathbf{R}$ from equation (3), as done by Menke [1989]:

$$
\begin{gathered}
\mathbf{C}_{\mathbf{m}}=\mathbf{G}^{-g} \mathbf{C}_{\mathbf{d}}\left(\mathbf{G}^{-g}\right)^{T} \\
\mathbf{R}=\mathbf{G}^{-g} \mathbf{G},
\end{gathered}
$$

with the error, or standard deviation, of the $i$ th model parameter being $\left(\sigma_{m}\right)_{i}$ with $\left(\left(\sigma_{m}\right)_{i}\right)^{2}=\left(C_{m}\right)_{i i}$ (see also Appendix B). Once $\mathbf{R}$ is obtained, it is possible to compute the spatial resolution of fault model following Funning et al. [2005].

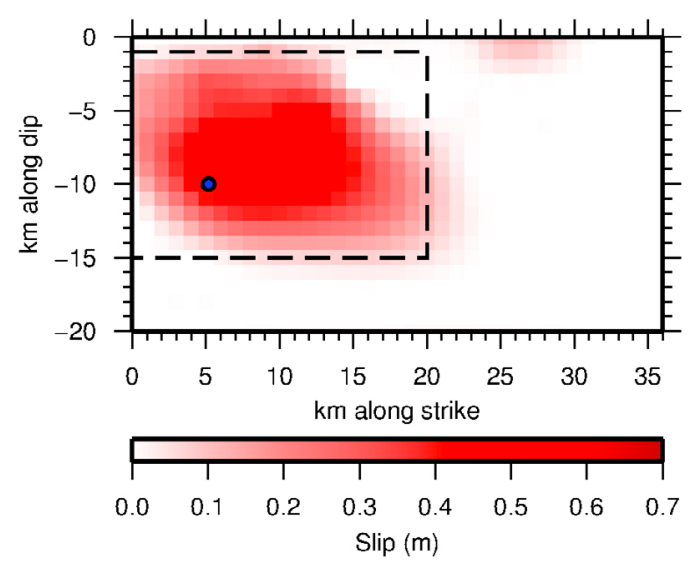

Figure 5. Slip distribution inferred for the fault model run 1 in Table 1. Results are from joint inversion of both vertical and eastward data. The dashed line represents the approximate position of the distributed fault used by Atzori et al. [2009]. The blue circle represents the position of the hypocenter projected on the fault. 


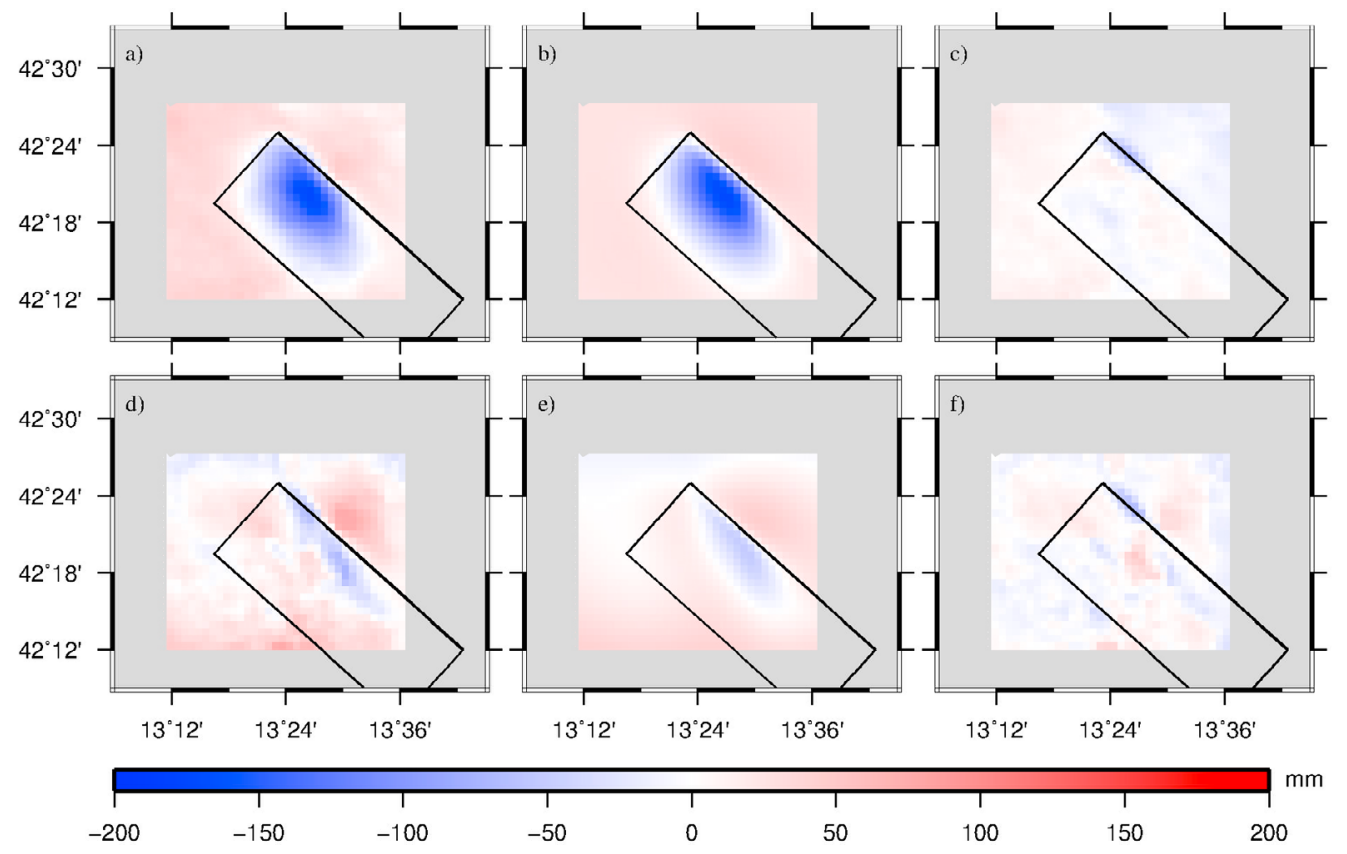

Figure 6. Data, modeled deformation, and misfit obtained from joint inversion of both vertical and eastward data, using fault model run 1 in Table 1. (a-c) Results for the vertical component. (d-f) Results for the eastward component.

[20] Only the main fault (6 April 2009, $M_{W}=6.3$ ) was considered, modeled as in Table 4. Surface dislocation was computed following the Okada [1985] model, using a rigidity modulus of $30 \mathrm{GPa}$ and a Poissonian solid model. A uniform error of $1 \mathrm{~cm}$ was imposed on the data, and a roughness limit of $15 \mathrm{~mm} \mathrm{~km}^{-1}$ was considered, since using more rough models do not significantly improve the misfit, as shown in Figure 4.

\section{Discussion}

[21] Availability of both vertical and horizontal eastward data sets over a wide area around the faulted area could

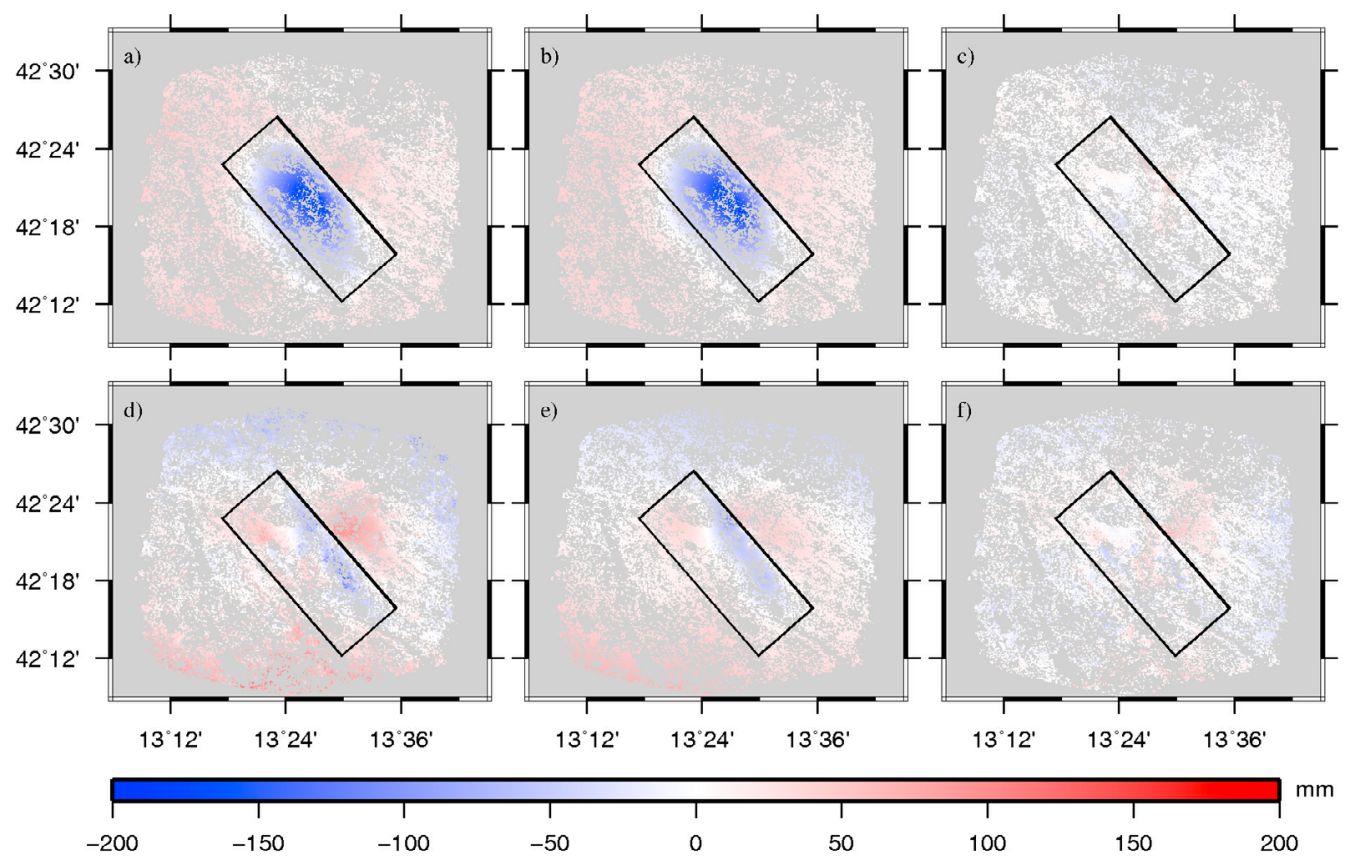

Figure 7. Data, modeled deformation, and misfit obtained from joint inversion of both vertical and eastward data, using fault model run 3 in Table 1. (a-c) Results for the vertical component. (d-f) Results for the eastward component. 


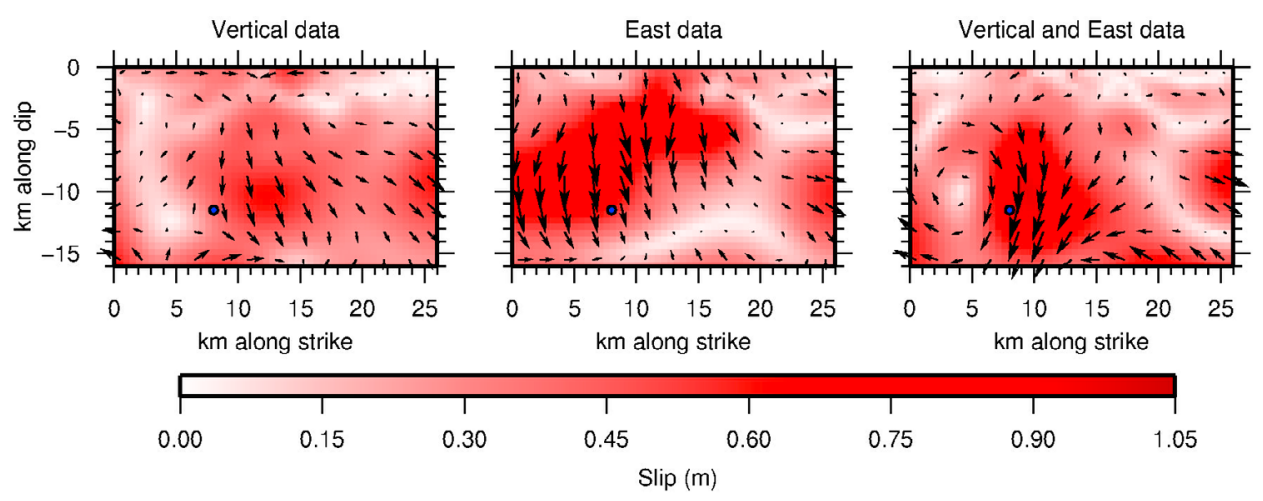

Figure 8. Slip distribution inferred for the fault model run 3 in Table 1. Results are from inversion of vertical data only, eastward data only, and the two joint data sets. The blue circles represent the position of the hypocenter projected on the fault.

provide a more complete description of the slip distribution over the fault, especially where no dense Global Navigation Satellite System (GNSS) network is operating. The case of the 2009 L'Aquila earthquake is suited to testing whether eastward DInSAR data can give new insights on slip distribution and characteristics over the fault with respect to previous works.

[22] Vertical and eastward displacement data are separately and jointly inverted here. In the first stage (run 1 in Tables 4 and 5) the original 197,555 data points were subsampled down to a subset of $926,1 \times 1 \mathrm{~km}^{2}$ blocks (displacement values averaged over each block), and an inversion of slip distribution over the fault (partitioned in $2 \times 2 \mathrm{~km}^{2},-103^{\circ}$ fixed rake angle over patches) was performed, using fault parameters and location similarly to Atzori et al. [2009] with a larger fault extension to account for possible side effects due to the smoothing process. The inverted slip distribution on the fault plane (Figure 5; model error and resolution are in Figure S2) is similar to the one obtained by Atzori et al. [2009], Guerrieri et al. [2010], or De Natale et al. [2011] as references, suggesting that the active area of the fault showing a significant dislocation is limited to about $20 \mathrm{~km} \times 16 \mathrm{~km}$. Resolution study shows that the southernmost and deepest part of the fault, outside the epicentral area, is completely unresolved. Model errors grow at the border of the modeled fault up to $3.5-4 \mathrm{~cm}$ in slip.

[23] Modeled surface displacement (Figures $6 \mathrm{~b}$ and 6e), faithfully reproduce the generally observed pattern (Figures 6a and $6 \mathrm{~d}$ ). Residuals (Figures 6c and 6f) are fairly low, with the exception of data points placed just NE of the northernmost corner of the fault, falling between the Paganica fault and the NW extension of the San Demetrio fault. This anomaly can be explained by noting that the choice for modeled fault of a strike angle and fault position as in the work by Atzori et al. [2009] suggests that the fault follows the San Demetrio fault. Such an alignment forces the badly modeled data points to partially lay on the footwall of the modeled fault, despite the fact that displacement shows a subsiding behavior in the vertical component and a strong westward motion. The misplacing of the modeled fault with respect to the observed displacement introduces an unrealistic reverse slip distribution over the northernmost portion of the fault that, once forcibly corrected in the inversion process, fails to model the vertical and horizontal data around the northernmost corner of the fault.

[24] We thus relocate the modeled fault in order to match the modeled fault position and strike with remotely sensed displacement patterns and field coseismic observations: the fault model derived from Atzori et al. [2009] follows the San Demetrio fault scarp, whereas the new fault model also accounts for the Paganica segments, aligned at a higher strike angle, where significant coseismic ground evidence was found. We performed a new inversion on a smaller fault, also taking into account variable rake on fault patches (run 2 in Tables 4 and 5). Residuals obtained from the relocated fault were smaller (results summarized in Table 5), particularly around the area close to the northernmost corner of the fault. Singly inverted vertical and eastward data sets are better reproduced by the model, with respect to the joint inversion (Figure S3). Despite the smaller fault area, here the inferred seismic moment is higher than in the case of run 1 and closer to the value obtained from CMT inversion $\left(3.66 \times 10^{18} \mathrm{Nm}, \mathrm{GCMT} ; 3.4 \times 10^{18} \mathrm{Nm}\right.$, USGS CMT solution; see also [Atzori et al., 2009] for further information). The highest slip obtained in inversion is approximately $0.6 \mathrm{~m}$ at the $15 \mathrm{~mm} \mathrm{~km}^{-1}$ roughness limit and rises with increasing permitted roughness, while the seismic moment does not change significantly in the $10-30 \mathrm{~mm} \mathrm{~km}^{-1}$ roughness range.

[25] In both joint and separate inversions of data sets, the rake distribution shows a dominant normal faulting mechanism around the maximum slip area (Figure S4), as already found by Atzori et al. [2009] or Guerrieri et al. [2010], but the rake variability also introduces a moderate right-lateral slip pattern in the lower southernmost portion of the fault, not found in previous inversions, and is more significant when eastward data is inverted. We think that this pattern could be an artifact generated by inverting surface displacement due to the Fossa event, which is not modeled in our inversion, as due to the Paganica fault.

[26] The Fossa event, dominated by a normal faulting mechanism but also showing a significant lateral component, probably originated on a fault antithetic to the Paganica fault, overprinting its southeastern part. Inverting the ground displacement due to the Fossa event as if it was due to the Paganica fault could lead to the unrealistic lateral slip at depth obtained in our variable rake inversion of the Paganica 


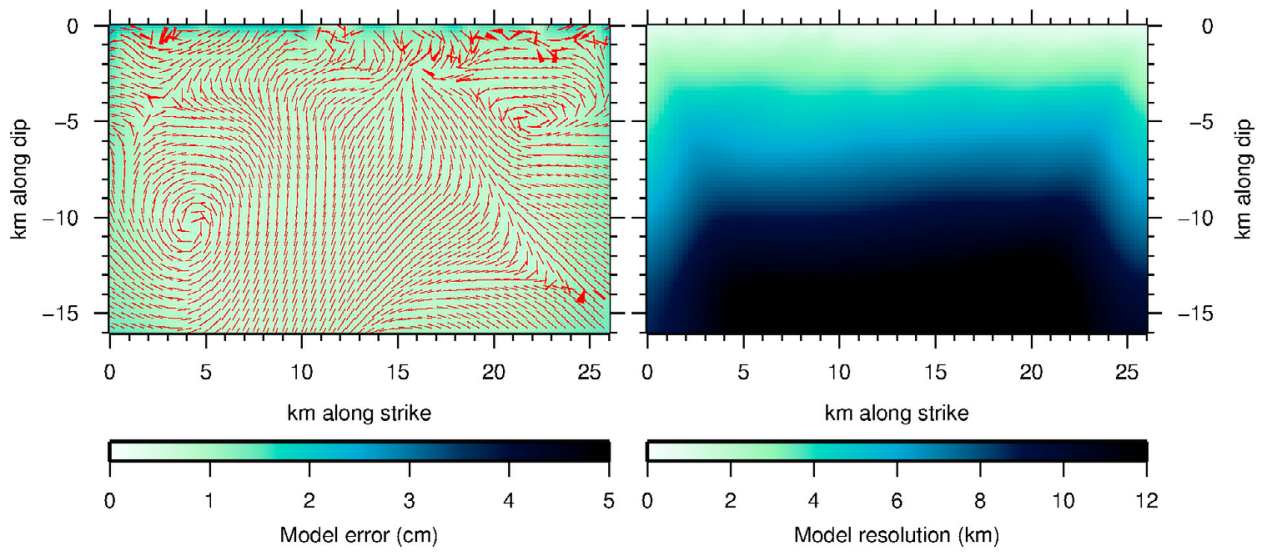

Figure 9. (left) Estimated model errors and (right) model spatial resolution inferred for the fault model run 3 in Table 1. Results are from inversion of vertical and eastward joint data sets. In Figure 9 (left), errors on rake angle are also depicted as red pie wedges.

fault. This hypothesis is also supported by the fact that the slip distribution inferred from seismological or GPS data, as done by Cirella et al. [2009], including only the main event, does not show such a deep structure and by the fact that residuals of our inversion overprinting that corner of the Paganica fault are still large, both in the E-W and in the vertical component. Another possible cause of erroneous modeling is the relatively reduced coherence of original DInSAR data in that part of the frame. Instability in inversion may come from the fact that the southernmost part of the fault is close to the boundary of the displacement data sets.

[27] Resolution and model error improve significantly with respect to run 1 (Figure S5), both in terms of higher resolving power and increased symmetry of resolution patterns. Resolution ranges from $2 \mathrm{~km}$ at surface to about $8 \mathrm{~km}$ at depth, whereas model errors are now lower than $2.5 \mathrm{~cm}$. Error estimates associated with rake angle (red pie wedges in Figure S5) are low, generally within $5^{\circ}$, except where nearly null slip is observed.

[28] Similar behavior is shown when full resolution $197,555,20 \times 20 \mathrm{~m}^{2}$ data points for both vertical and eastward components of surface displacement are considered (run 3 in Tables 4 and 5 and Figure 7). Data are singly and jointly inverted using the same fault characteristics of run 1 , the fault being divided into $14560.5 \times 0.5 \mathrm{~km}^{2}$ patches supporting variable rake. With respect to the run 1 and run 2 coarser models, chi square is greater for joint inversion. Since we obtain an excellent fit for vertical data, the higher misfit is mainly due to the badly modeled eastward component, in the form of all-around westward (light blue in Figure 7f) residuals in the far field and a reduced capability to reproduce eastward movements in the footwall of the Paganica fault (in red). Such misfit in the footwall is probably due to a real modeling defect, while the misfit in the far field, not present in run 2, could be ascribed to the high resolution of the data. Full resolution (not averaged) data sets could contain highly local effects that are not recoverable by the still-coarse patching of the fault. Furthermore, choosing a fixed $1 \mathrm{~cm}$ error for horizontal data as well could significantly raise the chi square value, if the error is underrated.
[29] Regarding the slip inversion (Figure 8; estimated model errors and resolution are shown in Figure 9), an important pattern of right-lateral slip also appears near the bottom right (southern) corner of the fault in inversion of high-resolution data with a variable rake model, but with a reduced magnitude with respect to run 2 . If such a

Table 6. Comparison Between GPS Data and Modeled Displacements According to Anzidei et al. [2009] and Results of Our Analysis Over the Same Points ${ }^{\mathrm{a}}$

\begin{tabular}{|c|c|c|c|c|c|c|}
\hline \multirow[b]{2}{*}{ Site } & \multicolumn{3}{|c|}{ GPS } & \multicolumn{3}{|c|}{ DInSAR } \\
\hline & $\begin{array}{l}\text { Obs } \\
(\mathrm{mm})\end{array}$ & $\begin{array}{c}\text { Err } \\
(\mathrm{mm})\end{array}$ & $\begin{array}{l}\text { Mod } \\
(\mathrm{mm})\end{array}$ & $\begin{array}{l}\text { Obs } \\
(\mathrm{mm})\end{array}$ & $\begin{array}{c}\text { Err } \\
(\mathrm{mm})\end{array}$ & $\begin{array}{c}\text { Mod } \\
(\mathrm{mm})\end{array}$ \\
\hline \multicolumn{7}{|c|}{ Eastward Data } \\
\hline AQUI & 9.0 & 2.1 & 9.0 & 33.6 & 10.0 & 28.6 \\
\hline CADO & -82.2 & 3.2 & -69.3 & -9.6 & 10.0 & -44.7 \\
\hline CPAG & 1.6 & 3.9 & 1.3 & 10.3 & 10.0 & 0.0 \\
\hline INGP & 5.5 & 2.1 & 5.3 & 25.5 & 10.0 & 15.4 \\
\hline INFN & 47.1 & 2.6 & 51.5 & 62.4 & 10.0 & 36.5 \\
\hline ROIO & 8.4 & 3.2 & -5.8 & -35.7 & 10.0 & 0.6 \\
\hline SELL & -11.4 & 3.7 & -7.3 & -23.5 & 10.0 & -22.8 \\
\hline SMCO & 0.4 & 3.2 & 0.7 & 6.2 & 10.0 & -6.0 \\
\hline \multicolumn{7}{|c|}{ North Data } \\
\hline AQUI & -42.4 & 2.1 & -39.5 & - & - & -16.7 \\
\hline CADO & 63.6 & 3.2 & 63.6 & - & - & 51.9 \\
\hline CPAG & -1.7 & 3.8 & -1.8 & _- & _- & -1.5 \\
\hline INGP & -23.9 & 2.1 & -23.7 & - & - & -9.4 \\
\hline INFN & 52.2 & 2.6 & 52.2 & - & - & 29.9 \\
\hline ROIO & -8.0 & 3.1 & -10.9 & - & - & 0.4 \\
\hline SELL & -3.8 & 3.7 & -4.4 & - & - & 1.4 \\
\hline SMCO & -11.6 & 3.2 & -12.1 & - & - & -0.8 \\
\hline \multicolumn{7}{|c|}{ Vertical Up Data } \\
\hline AQUI & -61.9 & 5.8 & -64.0 & -48.2 & 10.0 & -55.6 \\
\hline CADO & -156.4 & 15.5 & -185.8 & -123.2 & 10.0 & -145.4 \\
\hline CPAG & 15.8 & 13.7 & 3.9 & 10.2 & 10.0 & 4.6 \\
\hline INGP & -25.5 & 6.9 & -21.6 & -13.1 & 10.0 & -9.7 \\
\hline INFN & 26.0 & 5.5 & 15.9 & 14.0 & 10.0 & 14.0 \\
\hline ROIO & -117.4 & 8.2 & -153.1 & -109.8 & 10.0 & -109.8 \\
\hline SELL & 7.3 & 17.3 & -0.5 & 5.9 & 10.0 & 12.8 \\
\hline SMCO & 10.3 & 3.2 & -6.2 & 8.1 & 10.0 & 13.2 \\
\hline
\end{tabular}

${ }^{\mathrm{a}}$ The DInSAR data set is corrected for inferred residual tilts and biases. Obs, Err, and Mod stand for observed displacements, measurement uncertainties, and modeled displacements, respectively. 


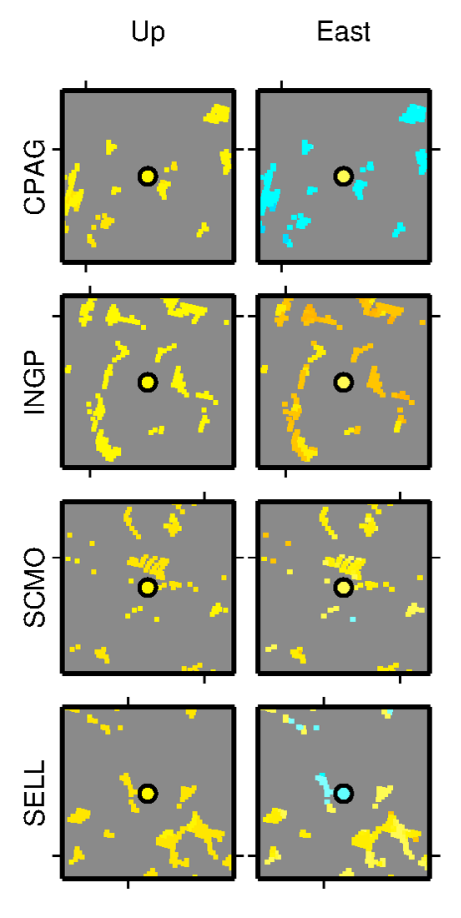

Up

East
$-100$
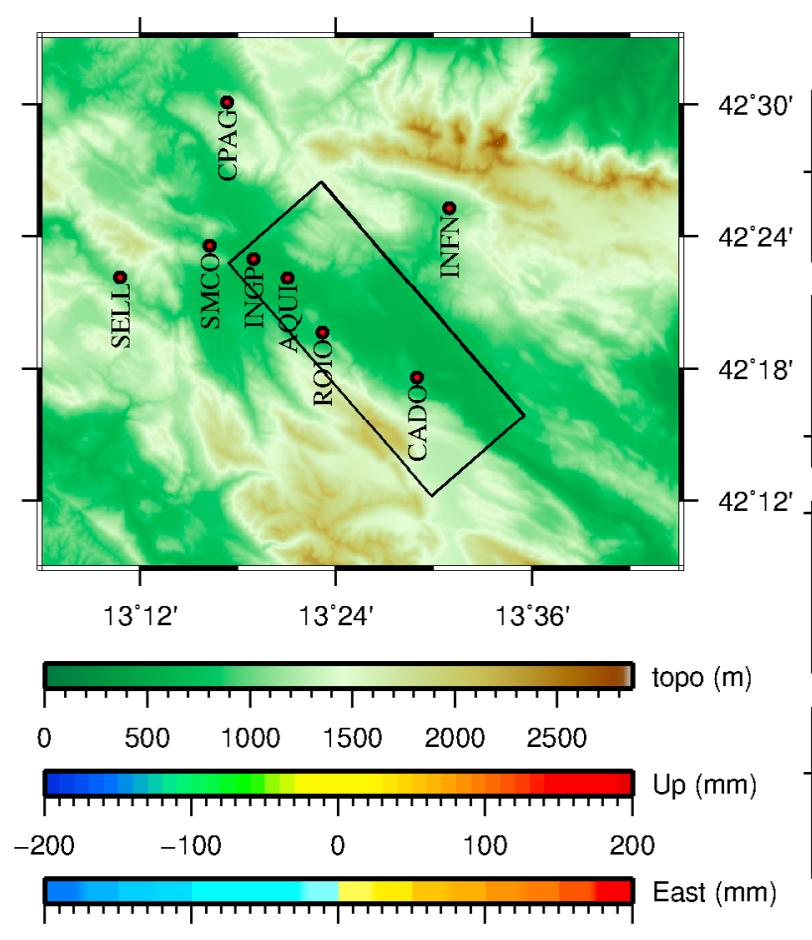

Up
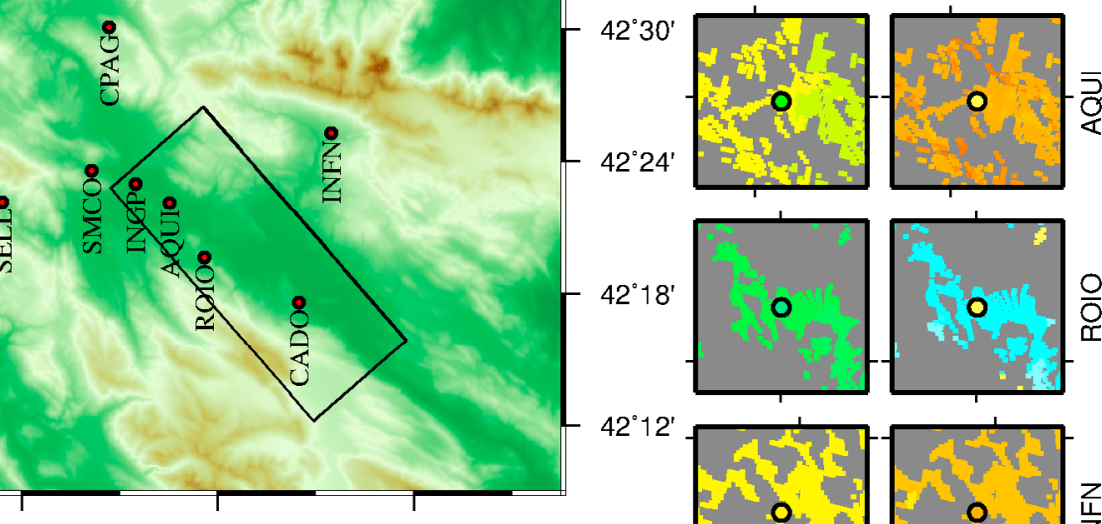

$13^{\circ} 12^{\prime}$

$13^{\circ} 24^{\prime}$

$13^{\circ} 36^{\prime}$

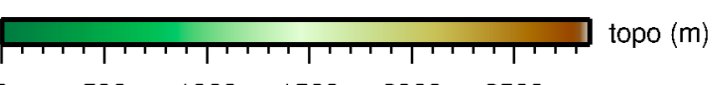

1000

1500

2000

2500
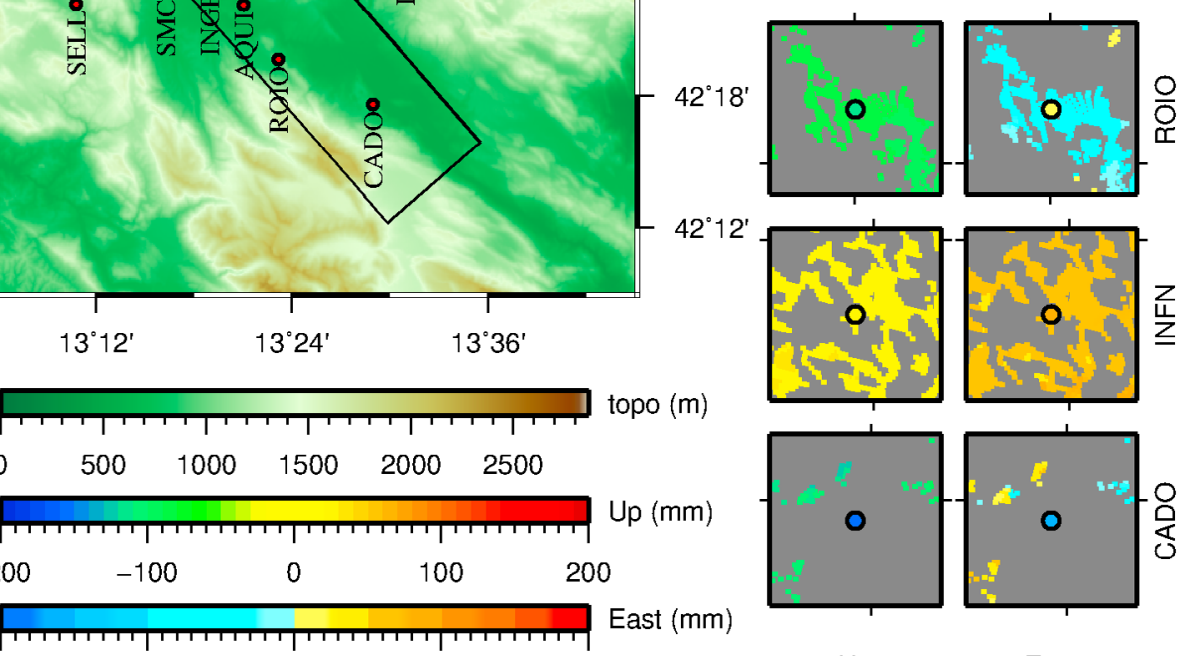

$42^{\circ} 12^{\prime}$

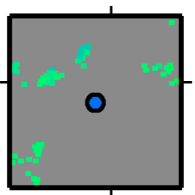

Up
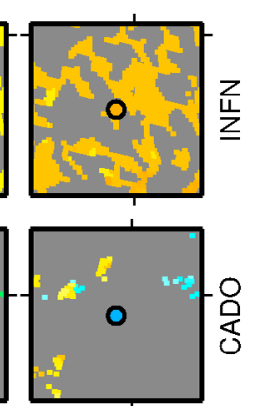

East

Figure 10. Position of GPS sites [after Anzidei et al., 2009] and comparison between GPS and DInSAR vertical and eastward displacements. The DInSAR data set is corrected for inferred residual tilts and biases. In each inset the GPS data point (outlined circle) is represented against DInSAR points (squares) over a $1 \mathrm{~km}^{2}$ box centered on a GPS site. Displacement values are represented in a color scale following the two different color bars for vertical and eastward data sets.

contribution is dropped, the total seismic moment approaches 3.4-3.6 $\times 10^{18} \mathrm{Nm}$, the value obtained from the CMT solution and rake angle values averaged over the fault result in a $-105^{\circ}$ rake angle (for eastward and joint data set inversion), which is close to the seismologically inferred one.

[30] The hypocenter is placed just below the maximum slip pattern, in the downdip direction, which falls in the range $4-8.5 \mathrm{~km}$ in depth. Superficial patches overprinting the superficial ruptures of the Paganica fault show a slip value of the order of $10-15 \mathrm{~cm}$, which is compatible with ground-observed deformation.

[31] Resolution analysis shows an improved model resolution at surface (now lower than $1 \mathrm{~km}$ ) with respect to run 2, but it rapidly increases with depth, letting the lowermost part of the fault completely unresolved $(12 \mathrm{~km})$, while there is a reduction in estimated model errors, down to about $1.5 \mathrm{~cm}$. Errors in rake angles are, also in this case, generally lower than $5^{\circ}$.

[32] Comparison between seismological results for rake and seismic moment release and ours shows that, in this case of a dominant normal-faulting mechanism, eastward data is more sensitive to rake variations, while vertical data give more information on slip values and distribution. The higher value of misfit obtained for joint inversion and the higher level of misfit coming from eastward data (with respect to vertical data) reveal that there is a slight, incurable, discrepancy between the information carried by the two data sets. The increased misfit for eastward data is possibly due to the simple, single-fault model of this paper compared to the capability shown by eastward data to resolve surface deformation due to distinct faults. Moreover, the real error for eastward data may be greater than that estimated. On the whole, when both data sets are used in inversion, the inferred slip distribution is closer to that obtained from vertical data alone (with respect to that inferred from eastward data alone) suggesting that for the 2009 L'Aquila event, described by a nearly pure dip-slip mechanism, the vertical component of displacement is dominant, not only in measured amplitudes, but also in the inversion process.

[33] The event on the Paganica fault clearly modified the state of stress in the seismogenic layer around the fault, as already noted by De Natale et al. [2011] in their exhaustive paper. We attempted to make a rough estimate of Coulomb static stress change due to the Paganica earthquake according to the method used by Dalla Via et al. [2007], projected on hypocenters of events that happened on the Laga mountain fault; inferred values for $\triangle C F F$ are in the range $0.06-0.08 \mathrm{MPa}$, almost half the value obtained for the 1997 Umbria-Marche event, but concordant with Walters et al.'s [2009] and De Natale et al.'s [2011] inferences. The static stress change thus promoted the activation of the LMFS.

\section{Comparison With GPS Data}

[34] Fault parameters have also been inferred by Anzidei et al. [2009] from displacement data measured over a network of more than 40 permanent GPS sites, in the near and 

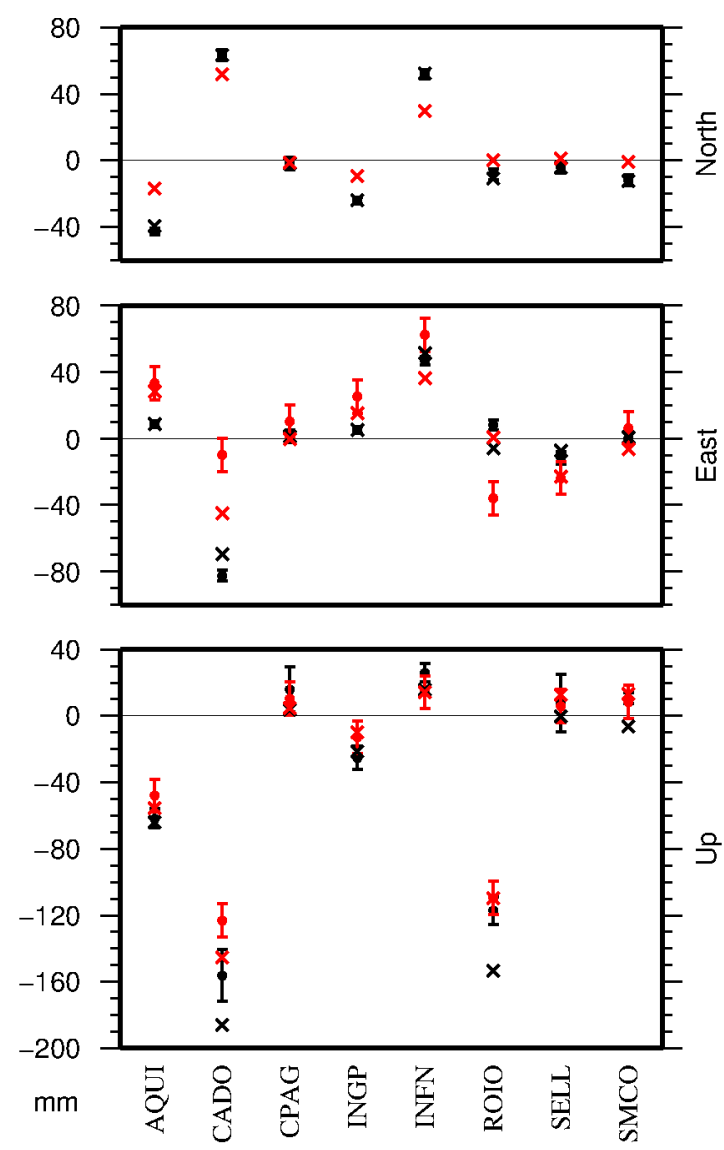

Figure 11. Comparison between GPS model and data (according to Anzidei et al. [2009]) and DInSAR model and data. The DInSAR data set is corrected for inferred residual tilts and biases. GPS is shown in black, and DInSAR is in red. Measured data with errors are depicted with error bars, and modeled dislocations are represented with crosses.

in the far fields. We used published data and results (8 nearfield GPS benchmarks providing east, north and vertical component of coseismic displacement) to perform a blind comparison between the independent GPS data set (and modeled displacement), our own data (for east and vertical components) and model results (for all components). The test was not trivial, since we compared a point-like GPS measurement with an areal mean of displacement obtained over the DInSAR pixel, in the best case, or with an interpolated value if there is no correspondence between GPS site and DInSAR pixel. Moreover, GPS data only include the main event, whereas DInSAR data sets also include the surface displacement field due to the Fossa event.

[35] In Table 6 and Figures 10 and 11 we compare GPS inferences to DInSAR models and data sets. With respect to Figure 7, a correction for residual tilts and offsets, as inferred by our joint inversion of vertical and eastward data sets, is applied to DInSAR data. The displacements recorded by GPS and DInSAR are similar in behavior, although there are significant differences in amplitude, especially for CADO and ROIO sites, exceeding GPS errors. A closer correspondence exists for vertical data, where the DInSAR model fits better not only to DInSAR data, but also GPS data. For eastward data, except for CADO and ROIO sites, DInSAR model fits well to DInSAR data and is close to GPS measurements, although the magnitude of the displacement is overestimated with respect to GPS. Since no DInSAR northward data set is available, we can constrain our model only along eastward and vertical projections. The modeled displacement in the northward component is thus completely unconstrained. Compared to the northward GPS displacement, the prediction by our DInSAR model is consistent in direction, but underestimated in magnitude.

[36] ROIO and CADO, the two sites showing the most significant differences, are also the ones closest to the Fossa event. DInSAR measured surface displacement might be affected by the Fossa event, especially in the eastward component. Despite the differences in data sets, it is noteworthy that, if a low level of roughness is allowed in our inversion scheme to simulate a uniform slip over the fault as modeled by Anzidei et al. [2009], we obtain a seismic moment of $3.17 \times 10^{18} \mathrm{Nm}$, close to their $3.2 \times 10^{18} \mathrm{Nm}$. This suggests that the eastward DInSAR data set is as informative as GPS for obtaining the seismic moment of this event.

\section{Conclusions}

[37] The availability of a high-density data set of eastward displacement data all over the epicentral area is an important improvement for obtaining a full-featured, variable rake slip model for the 2009 L'Aquila earthquake. Slip patterns are coherent with previous results if a fixed rake model is considered, but a deep left-lateral slipping patch is found when rake is inverted. Inferred rake of $-105^{\circ}$ is close to the CMT solution if eastward data are inverted, while the total seismic moment is coherent with the seismologically inferred one if only vertical data or joint vertical and eastward components are considered $\left(3.2-3.4 \times 10^{18} \mathrm{Nm}\right)$. This discrepancy seems to suggest that information carried by eastward and vertical data sets could be different and, to some extent, inconsistent, with eastward data being more informative than vertical data in the contributions of distinct faults.

[38] In all of our inversions we found that the superficial patches below the southern part of the Paganica fault show a nonnegligible slip of approximately $10-15 \mathrm{~cm}$, which is compatible with evidences observed on the surface. This suggests that activation of scarps on the surface along the Paganica fault may be a primary effect of faulting at depth reaching the surface, as already inferred by several authors in their variable slip models. Moreover, our findings show that slip distribution follows the Paganica fault more closely than the San Demetrio fault. Such a slip induced static stress change in the seismogenic layer and clearly promoted the activation of the LMFS (events 2, 4, and 5 in Table 1), as already noted by Walters et al. [2009] and De Natale et al. [2011].

[39] Blind comparison with GPS data used by Anzidei et al. [2009] can be considered positive, a good accordance having been found. A noteworthy similarity especially exists between vertical data sets and models, despite the complete independence between inverted data and the modeling procedure. There are two sites, namely ROIO and CADO, where accordance is not as good. Those sites are the two closest to the epicenter of the Fossa event and the misfit between SAR and GPS, both between models and observations, could be a consequence of the surface displacement caused by this event. In fact, ground perturbation induced 
by the Fossa event is not recorded in GPS data but affects DInSAR data sets and inverted models.

[40] Horizontal (eastward) spaceborne observations could thus give an ultimate advantage in imaging slip over faults in a complex faulted area, especially where no dense GNSS network is present and rake distribution is also an important variable to be determined. Furthermore, the joint inversion of dense vertical and eastward data sets is important to better understand complex faulted areas, making use of both higher resolution and complementary information given by vertical and horizontal data.

\section{Appendix A: Vertical and Eastward Components From DInSAR}

[41] Exploiting the two-phase deformation measures taken over the same point from descending and ascending orbit, we could retrieve the vertical and horizontal (only east-west direction) components of displacement. Considering that satellite positions are in the z-east plane, let $\theta_{a}$ and $\theta_{d}$ be the look angles for both orbit modes and $d$ the displacement of a surface point $P$. From the two displacements $\left(D_{d}\right.$ and $\left.D_{a}\right)$ measured along the LOS we can recover the vertical and horizontal components of the displacement $d$. A straightforward geometric calculus leads to the following expressions:

$$
\begin{aligned}
& d_{e}=\frac{D_{d} \cos \theta_{a}-D_{a} \cos \theta_{d}}{\sin \left(\theta_{a}+\theta_{d}\right)} \\
& d_{z}=\frac{D_{d} \sin \theta_{a}+D_{a} \sin \theta_{d}}{\sin \left(\theta_{a}+\theta_{d}\right)},
\end{aligned}
$$

in agreement with the expression by Manzo et al. [2006] when the two look angles are equal.

\section{Appendix B: Model Errors for Slip and Rake in Distributed Models}

[42] In our distributed slip, variable rake inversion scheme the along-dip and along-strike components of slip are inverted as separate model parameters for each patch. Let them be, for a generic patch, $d$ and $s$, respectively. Also model errors, introduced in section 4 as $\sigma_{m}$, are referred to as the along-dip and along-strike components of slip. Let the notation change here referring to such errors as $\delta_{d}$ and $\delta_{s}$, respectively. Since slip magnitude $m$ and rake angle $\alpha$ can be defined, in terms of $d$ and $s$, as

$$
\begin{gathered}
m=\sqrt{d^{2}+s^{2}} \\
\alpha=\arctan (-d / s),
\end{gathered}
$$

it is possible to obtain slip magnitude and rake angle errors, $\delta_{m}$ and $\delta_{\alpha}$, as

$$
\begin{gathered}
\delta_{m}=\sqrt{\left(\frac{\partial m}{\partial d} \delta_{d}\right)^{2}+\left(\frac{\partial m}{\partial s} \delta_{s}\right)^{2}}=\sqrt{\frac{d^{2} \delta_{d}^{2}}{s^{2}+d^{2}}+\frac{s^{2} \delta_{s}^{2}}{s^{2}+d^{2}}} \\
\delta_{\alpha}=\sqrt{\left(\frac{\partial \alpha}{\partial d} \delta_{d}\right)^{2}+\left(\frac{\partial \alpha}{\partial s} \delta_{s}\right)^{2}}=\sqrt{\frac{s^{2} \delta_{d}^{2}}{\left(d^{2}+s^{2}\right)^{2}}+\frac{d^{2} \delta_{s}^{2}}{\left(d^{2}+s^{2}\right)^{2}}}
\end{gathered}
$$

[43] Acknowledgments. The authors thank the European Space Agency (ESA) for distributing, free of charge, the ENVISAT SAR images of the L'Aquila (Italy) event, which were used in this work. The authors are also grateful to the Assistant Editor and two anonymous reviewers for their suggestions and constructive criticism, which helped improve the paper. This research has been developed in the framework of the ASI pilot project SISMA, "Information System for Monitoring and Alert," funded by the Italian Space Agency.

\section{References}

Anzidei, M., et al. (2009), Coseismic deformation of the destructive April 6, 2009 L'Aquila earthquake (central Italy) from GPS data, Geophys. Res. Lett., 36, L17307, doi:10.1029/2009GL039145.

Atzori, S., I. Hunstad, M. Chini, S. Salvi, C. Tolomei, C. Bignami, S. Stramondo, E. Trasatti, A. Antonioli, and E. Boschi (2009), Finite fault inversion of DInSAR coseismic displacement of the 2009 L'Aquila earthquake (central Italy), Geophys. Res. Lett., 36, L15305, doi:10.1029/ 2009GL039293.

Blumetti, A. M., V. Comerci, P. Di Manna, L. Guerrieri, and E. Vittori (2009), Geological effects induced by the L'Aquila earthquake (6 April $2009, \mathrm{Ml}=5.8$ ) in the natural environment, ISPRA report, 38 pp., Dip. Difesa del Suolo, Serv. Geol. d'Italia, Ist. Superiore per la Prot. e la Ric. Ambientale, Rome. [Available at http://www.isprambiente.gov.it/site/ en-GB/Projects/INQUA_Scale/Documents_/.]

Boncio, P., A. Pizzi, F. Brozzetti, G. Pomposo, G. Lavecchia, D. Di Naccio, and F. Ferrarini (2010), Coseismic ground deformation of the 6 April 2009 L'Aquila earthquake (central Italy, $\mathrm{M}_{w}$ 6.3), Geophys. Res. Lett., 37, L06308, doi:10.1029/2010GL042807.

Cheloni, D., et al. (2010), Coseismic and initial post-seismic slip of the $2009 \mathrm{M}_{w} 6.3$ L'Aquila earthquake, Italy, from GPS measurements, Geophys. J. Int., 181, 1539-1546, doi:10.1111/j.1365-246X.2010.04584.x.

Chen, C. W., and H. A. Zebker (2000), Network approaches to twodimensional phase unwrapping: Intractability and two new algorithms, J. Opt. Soc. Am., 17, 401-414, doi:10.1364/JOSAA.17.000401.

Chiarabba, C., et al. (2009), The 2009 L'Aquila (central Italy) $\mathrm{M}_{W} 6.3$ earthquake: Main shock and aftershocks, Geophys. Res. Lett., 36, L18308, doi:10.1029/2009GL039627.

Cirella, A., A. Piatanesi, M. Cocco, E. Tinti, L. Scognamiglio, A. Michelini, A. Lomax, and E. Boschi (2009), Rupture history of the 2009 L'Aquila (Italy) earthquake from non-linear joint inversion of strong motion and GPS data, Geophys. Res. Lett., 36, L19304, doi:10.1029/2009GL039795.

Costantini, M. (1998), A novel phase unwrapping method based on network programming, IEEE Trans. Geosci. Remote Sens., 36, 813-821.

D'Agostino, N., A. Avallone, D. Cheloni, E. D'Anastasio, S. Mantenuto, and G. Selvaggi (2008), Active tectonics of the Adriatic region from GPS and earthquake slip vectors, J. Geophys. Res., 113, B12413, doi:10.1029/2008JB005860.

Dalla Via, G., B. Crippa, E. M. Toraldo Serra, G. Giacomuzzi, and R. Sabadini (2007), Exploitation of high-density DInSAR data points of the UmbriaMarche (Italy) 1997 seismic sequence for fault characteristics, Geophys. Res. Lett., 34, L17301, doi:10.1029/2007GL030718

deGroot-Hedlin, C., and S. Constable (1990), Occam's inversion to generate smooth, two-dimensional models for magnetotelluric data, Geophysics, 55(12), 1613-1624.

De Natale, G., B. Crippa, C. Troise, and F. Pingue (2011), Abruzzo, Italy, earthquakes of April 2009: Heterogeneous fault-slip models and stress transfer from accurate inversion of ENVISAT-InSAR data, Bull. Seismol. Soc. Am., 101(5), 2340-2354, doi:10.1705/0120100220.

Di Luccio, F., G. Ventura, R. Di Giovambattista, A. Piscini, and F. R. Cinti (2010), Normal faults and thrusts reactivated by deep fluids: The 6 April $2009 M_{w}$ 6.3 L'Aquila earthquake, central Italy J. Geophys. Res., 115, B06315, doi:10.1029/2009JB007190.

EMERGEO Working Group (2010), Evidence for surface rupture associated with the Mw 6.3 L'Aquila earthquake sequence of April 2009 (central Italy), Terra Nova, 22(1), 43-51, doi:10.1111/j.1365-3121.2009.00915.x. Falcucci, E., et al. (2009), The Paganica fault and surface coseismic ruptures caused by the 6 April 2009 earthquake (L'Aquila, central Italy), Seismol. Res. Lett., 80(6), 940-950, doi:10.1785/gssrl.80.6.940.

Fialko, Y., M. Simons, and D. Agnew (2001), The complete (3-D) surface displacement field in the epicentral area of the $1999 M_{w} 7.1$ Hector Mine earthquake, California, from space geodetic observations, Geophys. Res. Lett., 28(16), 3063-3066, doi:10.1029/2001GL013174.

Funning, G. J., B. Parsons, T. J. Wright, J. A. Jackson, and E. J. Fielding (2005), Surface displacements and source parameters of the 2003 Bam (Iran) earthquake from ENVISAT advanced synthetic aperture radar imagery, J. Geophys. Res., 110, B09406, doi:10.1029/2004JB003338. 
Galli, P., B. Giaccio, and P. Messina (2010), The 2009 central Italy earthquake seen through 0.5 Myr-long tectonic history of the L'Aquila faults system, Quat. Sci. Rev., 29, 3768-3789, doi:10.1016/j.quascirev.2010.08.018.

Galli, P. A. C., B. Giaccio, P. Messina, E. Peronace, and G. M. Zuppi (2011), Palaeoseismology of the L'Aquila faults (central Italy, 2009, $M_{w} 6.3$ earthquake): Implications for active fault linkage, Geophys. J. Int., 187, 1119-1134, doi:10.1111/j.1365-246X.2011.05233.x.

Guerrieri, L., et al. (2010), InSAR data as a field guide for mapping minor earthquake surface ruptures: Ground displacements along the Paganica fault during the 6 April 2009 L'Aquila earthquake, J. Geophys. Res., 115, B12331, doi:10.1029/2010JB007579.

Jonsson, S., H. Zebker, P. Segall, and F. Amelung (2002), Fault slip distribution of the $1999 \mathrm{Mw} 7.1$ Hector Mine, California, earthquake, estimated from satellite radar and GPS measurements, Bull. Seismol. Soc. Am., 92(4), 1377-1389.

Manzo, M., G. P. Ricciardi, F. Casu, G. Ventura, G. Zeni, S. Borgstrom, P. Berardino, C. Del Gaudio, and R. Lanari (2006), Surface deformation analysis in the Ischia Island (Italy) based on spaceborne radar interferometry, J. Volcanol. Geotherm. Res., 151(4), 399-416, doi:10.1016/j. jvolgeores.2005.09.010.

Massonnet, D., M. Rossi, C. Carmona, F. Ardagna, G. Peltzer, K. Feigl, and T. Rabaute (1993), The displacement field of the Landers earthquake mapped by radar interferometry, Nature, 364, 138-142.

Menke, W. (1989), Geophysical Data Analysis: Discrete Inverse Theory, Int. Geophys. Ser., vol. 45, revised edition, 289 pp., Academic, San Diego, Calif.

Okada, Y. (1985), Surface deformation due to shear and tensile faults in a half-space, Bull. Seismol. Soc. Am., 75, 1135-1154.
Pino, N. A., and F. Di Luccio (2009), Source complexity of the 6 April 2009 L'Aquila (central Italy) earthquake and its strongest aftershock revealed by elementary seismological analysis, Geophys. Res. Lett., 36 , L23305, doi:10.1029/2009GL041331.

Trasatti, E., C. Kyriakopoulos, and M. Chini (2011), Finite element inversion of DInSAR data from the Mw 6.3 L'Aquila earthquake, 2009 (Italy), Geophys. Res. Lett., 38, L08306, doi:10.1029/2011GL046714.

Walters, R. J., J. R. Elliott, N. D’Agostino, P. C. England, I. Hunstad, J. A. Jackson, B. Parsons, R. J. Phillips, and G. Roberts (2009), The 2009 L'Aquila earthquake (central Italy): A source mechanism and implications for seismic hazard, Geophys. Res. Lett., 36, L17312, doi:10.1029/ 2009 GL039337.

Wilkinson, M., et al. (2010), Partitioned postseismic deformation associated with the $2009 \mathrm{Mw} 6.3 \mathrm{~L}$ 'Aquila earthquake surface rupture measured using a terrestrial laser scanner, Geophys. Res. Lett., 37, L10309, doi:10.1029/2010GL043099.

Wright, T. J., B. E. Parsons, and Z. Lu (2004), Toward mapping surface deformation in three dimensions using InSAR, Geophys. Res. Lett., 31, L01607, doi:10.1029/2003GL018827.

B. Crippa, Department of Earth Sciences “A. Desio,” Università degli Studi di Milano, Via L. Cicognara 7, I-20129 Milan, Italy. (bruno. crippa@unimi.it)

M. Crosetto, Institute of Geomatics, Parc Mediterrani de la Tecnologia, Avinguda Gauss 11, Castelldefels, E-08860 Barcelona, Spain. (michele. crosetto@ideg.es)

G. Dalla Via, Department of Physics, Politecnico di Milano, Piazza Leonardo da Vinci 32, I-20133 Milan, Italy. (giorgio.dallavia@polimi.it) 